PALIVIZUMAB PROPHYLAXIS FOR VRS INFECTION IN PRETERM INFANTS WITH GESTATIONAL AGE $\leq 30$ WEEKS: COMPLIANCE, EFFICACY AND ADVERSE EVENTS

F. Serrao, F. Gallini, F. Cota, L. Maggio, F. Fusco, M.P. De Carolis, C. Romagnoli

Division of Neonatology -Department of Paediatrics, University Hospital "Agostino Gemelli"- Catholic University Sacred Heart, Rome, Italy

Background: Among extremely premature infants data related to compliance, efficacy and adverse events of Palivizumab (PVZ) prophylaxis are still poor. Aim of the study was to evaluate the compliance of the families, the prevalence of hospitalizations in the first two years of life and the prevalence of correlated serious adverse events in a population of extremely preterm infants submitted to prophylaxis with Palivizumab.

Methods: 211 preterm infants with gestational age (GA) $\leq 30$ weeks discharged in 4 epidemic seasons (2004-2008) were included in the study.

Results: 205 infants $(97,1 \%)$ received the prophylaxis with PVZ in the first year of life; 177 infants $(86,3 \%)$ received all the anticipated PVZ administrations at the planned intervals. All infants with BPD (25/205) performed the prophylaxis also in the second year. In 4 infants $(1,9 \%)$ severe and correlated adverse events were recordered. The total hospitalization rates resulted $30,7 \%$ and $10,7 \%$ respectively in the first and second year of life. RSV hospitalization rates was $2,4 \%$ in the first year of life; no hospitalization for RSV was registered in the second year.

Conclusions: In our population of infants with GA $\leq 30$ weeks PVZ prophilaxis is a well tolerated strategy of intervention, associated with a low rate of severe adverse events and uncommon RSV related hospitalizations.

\section{DNA DETECTION OF CARIOGENIC AND PERIODONTAL PATHOGENS IN THE SALIVA OF NEWBORNS AND SIX MONTH OLD INFANTS}

\author{
V. Merglova ${ }^{1}$, J. Dort ${ }^{2}$, P. Stunova ${ }^{2}$ \\ ${ }^{1}$ Department of Stomatology, ${ }^{2}$ Department of \\ Neonatology, Charles University Hospital, \\ Pilsen, Czech Republic
}

Aim: The aim of our study was to identify known cariogenic and periodontal pathogens in the saliva of newborns and six months old predentate infants.

Study groups and methods: 25 newborns threeday-old (group A) and 17 six-month-old predentate infants (group B) were randomly selected to our study. Particular samples of the saliva from mucosal surfaces of oral cavity were used for detection of cariogenic and periodontal pathogens. Bacterial species were identified using PCR based method (test Stoma Gene ${ }^{\circledR}$ ).

Results: The cariogenic microbes (Streptococcus mutans, Lactobacillus spp., Actinomyces spp.) were the most frequently isolated bacteria in both groups. $76 \%$ of newborns in the group A and $82 \%$ of infants in the group B had some species of cariogenic microorganisms (mainly Streptococcus mutans) in saliva. The periodontal pathogens (Actinobacillus actinomycetemcomitans, Prevotella intermedia, Fusobacterium nucleatum) were not found in the group A but in the group B (in $53 \%$ ), however.

Conclusions: Our findings have confirmed early transmission of cariogenic and periodontal pathogens to oral cavity of predentate infants. The presence of these microbes represents a risk factor for early childhood caries and early onset periodontal disease.

Supported by grant IGA Health Ministry of Czech Republic NS/9732 - 3. 